\title{
Effect of steroid hormones on the peripheral nervous system
}

\author{
M. Koszykowska ${ }^{1}$, J. Wojtkiewicz ${ }^{2}$, M. Majewski ${ }^{2}$ and B. Jana ${ }^{1,3}$ \\ ${ }^{1}$ Institute of Animal Reproduction and Food Research, Polish Academy of Sciences, \\ Division of Reproductive Endocrinology and Pathophysiology \\ 10-747 Olsztyn, Tuwima 10, Poland \\ ${ }^{2}$ University of Warmia and Mazury, Division of Clinical Physiology, \\ Department of Functional Morphology, Faculty of Veterinary Medicine \\ Oczapowskiego 13, 10-719 Olsztyn, Poland
}

(Received 12 April 2007; revised version 17 December 2007; accepted 15 January 2008)

\begin{abstract}
The aim of the present review is to describe the localization and expression pattern of oestrogens, androgens and progestagens receptors within the rat peripheral nervous system (PNS), and to emphasize the important role of these steroids in regulation of peripheral neurons function(s). Till now, steroid receptors were found predominantly in a subset of sensory and autonomic PNS cells projecting to reproductive organs and/or urinary system, as well as in Schwann cells of the sciatic nerve. Available literature strongly suggests that oestrogens exert diverse effects on sensory and autonomic neurons, among others influencing not only the development, plasticity and repair abilities of dorsal root ganglia neurons, but also controlling the neuritogenesis of sympathetic neurons and Schwann cell proliferation. Furthermore, there is growing body of evidence that these steroids are also able to change the neurochemical architecture of circuits involved in analgesia and nociception, most probably by modulation of the chemical coding of sensory and autonomic neurons. In contrast, there is a paucity of data concerning the function(s) of androgens and progestagens on PNS neurons. As of now, while androgens are thought to exert strong impact on the morphology, chemical phenotypes and function(s) of pelvic autonomic neurons, involved in reproductive behaviours in male, progestagens are implicated to influence the somatosensory pathways rather, being able to act on morphology of sciatic nerves (e.g., influencing expression of myelin proteins and Schwann cell proliferation). Thus, although there is no doubt that an immediate bilateral relationship between the peripheral nervous and endocrine systems exists, it should be stressed that available data are restricted only to experiments performed on rats, in this way limiting the scope of this short review to this species only.
\end{abstract}

KEY WORDS: peripheral nervous system, steroid hormones, steroid receptors, autonomic neurons, sensory neurons

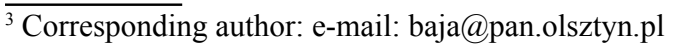




\section{INTRODUCTION}

It is generally accepted that an immediate bilateral relationship between the nervous and endocrine systems exist in all mammalian species, however, the available data are restricted only to rat. Thus, while neurotransmitters, released by autonomic and sensory nerve terminals are able to affect gland cells, evoking profound changes in the synthesis rate of steroid hormones, the same peripheral neurons are under continuous influence of steroids synthesized by the gland cells. As may be judged from available literature, while the effect of various steroids on central nervous system (CNS) functions is, as of now, already considerably recognized, there is a lack in our knowledge considering the influence of steroid hormones on the development, plasticity and activity of the PNS neurons.

Thus, the aim of the current short review is to provide the reader with available data considering both the localization and expression pattern of oestrogen (ERs), androgen (ARs) and progestagen (PRs) receptors in the PNS, as well as with information focussing on the effect of mentioned steroids on neuronal functions of the PNS neurons in the rat, the sole species studied in this respect so far.

\section{LOCALIZATION, EXPRESSION PATTERN AND PUTATIVE FUNCTIONS OF OESTROGEN RECEPTORS (ERs) IN THE PNS}

\section{Distribution pattern of ERs in autonomic and sensory neurons}

Expression of ER $\alpha$ was detected in approximately $30 \%$ of all dorsal root ganglia (DRG) primary sensory neurons of 3-4 days old female rats, whereas approximately $50 \%$ of studied cells were positive for ER $\beta$. Both receptors showed a clear nuclear localization; however, in some cases they may also be detected in cytosol. Moreover, it has been shown that an exposure of cultured DRG neurons, obtained from these animals, to the cognate ligand $\mathrm{E}_{2}$ caused a down-regulation of both subtypes of receptors (Patrone et al., 1999), what was also found in cultures of adult DRG neurons obtained from male and female rats. In these animals, ER $\beta$ mRNA was widely expressed in the L6-S1 DRG small-, medium- and large-sized neurons. In turn, ER $\alpha$ mRNA as well as ER $\alpha$ protein were localized especially in nuclei of small-sized neurons and were rarely present in large cells (Taleghany et al., 1999). Moreover, it has been shown in the rat that approximately $17 \%$ afferent neurons at the L6-S1 levels contained ER $\alpha$, approximately $23 \%$ contained ER $\beta$, and approximately $5 \%$ neurons expressed both subtypes of ERs (Papka and Storey-Workley, 2002). It is important to emphasize that in intact rats the pattern of ERs expression in DRG neurons changed in dependence on the day of oestrous cycle. $E R \alpha$ and $E R \beta$ mRNAs expression was found higher during the proestrous, 
than that observed in metaoestrous. Furthermore, a long-term oestrogen treatment of ovariectomized (OVX) rats dramatically reduced both the detectable level of ER $\alpha$ mRNA and ER $\alpha$ protein in the DRG neurons, while up-regulates the level of ER $\beta$ mRNA in these cells (Taleghany et al., 1999). It has also been found that ER $\beta$ mRNA level in DRG neurons remains largely unchanged throughout the course of pregnancy, whereas the amount of ER $\alpha$ mRNA rises near term (Mowa et al., 2003a, b).

Expression of ERs subtypes in sympathetic neurons of pre- and paravertebral ganglia was found by Zoubina and Smith (2002). ER $\alpha$-immunoreactivity (IR) was present in approximately $30 \%$ of neurons, while ER $\beta$ was expressed by approximately $93 \%$ of all sympathetic perikarya. The above-described proportion of neurons expressing these receptors was comparable to this found in the superior cervical and paravertebral ganglia (at neuromers T11-L5), as well as in suprarenal, celiac, and superior mesenteric prevertebral ganglia. Uterus-projecting neurons located in T13 and L1, as well in the suprarenal ganglion, showed small, but significantly greater incidence of ER $\beta$ expression in relation to the whole neuronal population, whereas the proportion of uterus-projecting neurons expressing ER $\alpha$ IR was nearly threefold higher. It has also been demonstrated that acute oestrogen administration did not significantly affect the number of ERs-expressing sympathetic neurons in pre- and paravertebral ganglia.

ERs-IR and ERs mRNA transcripts were also present in subpopulations of parasympathetic neurons of pelvic (PG; Papka et al., 2001; Purves-Tyson et al., 2007 ) as well as sensory nodose ganglia (NG); interestingly, ERs-immunostaining was more prominent in neurons of OVX than of intact rats. It has been shown that in both the PG and NG, neurons contained ERs (visualized as dark or intensely staining within the nucleus) were scattered throughout the ganglia without any somatotopic pattern (Papka et al., 1997, 2001). Using immunohistochemical visualization it has been demonstrated that ER $\alpha$ transcript is predominantly expressed by nitric oxide synthase (NOS)-positive parasympathetic PG neurons of male rats (Purves-Tyson et al., 2007). Many ovary-projecting celiac ganglia (CG) neurons exhibited also ER $\alpha$. These cells were scattered throughout the ganglion without any somatotopic distribution pattern. The number of CG cells harboring ERs selectively decreased after prenatal diethylstilbestrol exposure (Shinohara et al., 2000).

Moreover, it has also been shown in female rats that ER $\alpha$ - and ER $\beta$-IR was expressed by pre- and T11-L5 paravertebral sympathetic neurons supplying the proximal urethra. In these animals, ER $\beta$ was detected in more than $90 \%$ of urethra-projecting neurons, while approximately $30 \%$ of studied sympathetic neurons expressed also ER $\alpha$. Although ERs-IR was mainly confined to the nuclei of these neurons, it was also observed in the cytoplasm of a subset of them. There were no relationships between the number of ER $\alpha$-IR neurons and either the ganglion of 
origin, or the circulating oestrogen level - it has been demonstrated that virtually all of examined sympathetic neurons expressed ER $\beta$ and a substantial subset of them expressed simultaneously ER $\alpha$, irrespective of low (OVX rats) or high (single injection of oestradiol-17 $\beta-\mathrm{E}_{2}$ ) oestrogen titter (Zoubina and Smith, 2003).

ERs expression in urinary bladder-supplying lumbosacral DRG neurons of adult female rats was demonstrated for the first time by Bennett et al. (2003). Both ER $\alpha$ and ER $\beta$ subtypes were found in numerous sensory neurons of either upper lumbar (L1 and L2) or lower lumbar/sacral (L6-S1) ganglia. Immunolabelling with antibodies raised against both subtypes of ERs demonstrated a virtually total coexistence of these two receptors in primary sensory cells. For example, all ER $\alpha$-IR neurons in L1 and L2 DRG contained ER $\beta$, while $98 \%$ of ER $\beta$ neurons contained simultaneously ER $\alpha$. Similarly, all ER $\alpha$-positive neurons in L6-S1 ganglia contained ER $\beta$, while $97 \%$ of ER $\beta$-IR neurons contained ER $\alpha$. Moreover, although ERs-IR was observed in all classes of L1 DRG sensory neurons, the majority of ERs-positive neurons belonged to the small $(<18 \mu \mathrm{m})$ and medium $(18-25 \mu \mathrm{m})$ perikarya. ERs-IR was typically indicated by distinct nuclear staining, however, in some neurons cytoplasmic labelling was also observed.

In Schwann cells of rat sciatic nerves ERs were located in whole cells; however, most of the ERs-IR was present in the cytoplasm. Exposure of Schwann cells to $E_{2}$ resulted in a distinct increase in nuclear staining, suggesting that the receptor is nuclear as observed in classical target cells (Jung-Testas et al., 1993, 1996). Moreover, according to Thi et al. (1998) presence ERs in co-cultures of DRG neurons and Schwann cells of the sciatic nerves indicates important role oestrogens in the functions of these nerves (details are given below).

\section{Effect of $E_{2}$ on the development, survival, plasticity and repair of sensory neurons}

Patrone et al. (1999) have revealed that $\mathrm{E}_{2}$ and their receptors take part in the regulation of developing and survival of sensory DRG neurons. Thus, $\mathrm{E}_{2}$ treatment of cultured postnatal DRG neurons leads to the delay in neuronal cell death after nerve growth factor withdrawal (NGF; an "classical" an indispensable neurotrophic factor for these neurons, crucial for their growth, survival and differentiation; Oppenheim, 1991; Nicol and Vasko, 2007). Although it has been shown by means of ICI 182,780 (a specific ERs antagonist) treatment that $\mathrm{E}_{2}$ is not able to counteract NGF deprivation-induced cell death of DRG neurons per se, it is able to induce a strong up-regulation of $\mathrm{Bcl}-\mathrm{xL}$ protein (antiapoptotic protein, promoting cell survival) in sensory perikarya, while Bax (proapoptotic protein, inducing cell death) expression remained constant (Vogelbaum et al., 1998). Furthermore, exposition of cultured DRG cells to tamoxifen (an antioestrogen) completely blocked the action of $\mathrm{E}_{2}$ on sensory perikarya, indicating that ERs activation is 
instrumental for the hormone to protect DRG neurons. It is worth to mention that in contrary to $\mathrm{E}_{2}$, NGF failed to increase the level of Bcl-xL in DRG neurons, thus suggesting that both compounds are acting through two independent, but closely related pathways promoting sensory neurons survival. This has been substantiated by data revealing an additive effect on cell survival exerted by $\mathrm{E}_{2}$ and a low dose of NGF (Patrone et al., 1999). Furthermore, the study of DRG neurons obtained from adult rats revealed a crosstalk between oestrogens and NGF what is associated with regulation of NGF receptor expression by these steroids. Thus, $\mathrm{E}_{2}$ replacement in OVX animals conducted to down-regulate ERs mRNA and p75 mRNA (with low-affinity), but up-regulate time-dependently TrkA mRNA (with high-affinity) level in these cells (Sohrabji et al., 1994).

Furthermore, it has been reported that $\mathrm{E}_{2}$ has also a beneficial effect on peripheral nerve regeneration (Bajusz, 1959) what is consistent with the hypothesis that $\mathrm{E}_{2}$, via interactions with growth factors known to ameliorate injury of the adult PNS (e.g., neurotrophins), may also have stimulatory influence on regenerative processes following neurite damage (Sohrabji et al., 1994). Scoville et al. (1997) have revealed that neurofilaments (major structural components of larger DRG neurons, essential to the maintenance of neuronal size, shape and axonal diameter and thereby, axonal conduction velocity) gene expression in DRG neurons is not only dependent on NGF receptor expression, but also on oestrogens availability. These steroids have thus been shown to dose-dependently increase neurofilament gene expression in all DRG neurons, however, neurons with larger diameters appeared to display a more dramatic increase in neurofilament mRNA steady-state levels in response to oestrogens treatment than the medium- and small-sized perikarya.

\section{Effect of $E_{2}$ on the neuritogenesis of autonomic neurons and Schwann cell prolif-} eration

As may be judged from the available literature, $\mathrm{E}_{2}$ has a growth-inhibitory effect on uterine sympathetic nerves, but the response to this steroid is dependent on neuron-target interactions. It has been reported i.a. that chronic exposure to $E_{2}$ in rats during the infantile and prepubertal period lead to a complete loss of noradrenergic intrauterine nerves (Brauer et al., 2000; Chávez-Genaro et al., 2002). It should, however, be stressed that although an early exposure of rats to $\mathrm{E}_{2}$ did not inhibit the ingrowth of sympathetic nerves to the uterus, it is able to prevent the normal growth and maturation of these fibres. Moreover, $\mathrm{E}_{2}$ lead to retraction or degeneration of the immature intrauterine nerve fibres that reached the organ before initiation of this steroid administration. It has also been revealed that perivascular and myometrial fibres were absent from uteri of either intact and OVX rats after 3 months of $\mathrm{E}_{2}$ administration no, while they were still present around blood vessels and smooth muscles of the mesometrium. However, after 6 months of $E_{2}$ treatment 
a very modest and not organotypical regrowth of the innervation was observed near blood vessels of uterine horns and in the antimesometrial border of the longitudinal myometrial layer. Till now, this phenomenon may be explained by hypothesis that $\mathrm{E}_{2}$ could impair uterine sympathetic innervation, directly acting on nerve fibres (Brauer et al., 2000, 2002) or else on ganglia. Moreover, it is interesting that, a pituitary-derived hormone (possibly prolactin) blocks oestrogen's inhibition of neurite formation. Oestrogens (height level), in turn, can abolish the action of the pituitary-derived hormone, presumably by acting on the pituitary gland to inhibit its release (Krizsan-Agbas and Smith, 2002). $E_{2}$ is also able to stimulate proliferation of Schwann cells originating from adult and newborn male rats sciatic nerves, but do not exert any effect on such cells from adult female rats. This was further substantiated by data indicating that stimulatory effect of $E_{2}$ was blocked by the use of a specific ERs blocker in vitro (Svenningsen and Kanje, 1999).

\section{Effect of $E_{2}$ on the chemical coding of sensory neurons supplying female reproduc- tive organs}

It has previously been shown that $\mathrm{E}_{2}$ is able to modulate the synthesis rate of various neuropeptides in DRG sensory neurons supplying female reproductive organs (Schmitt et al., 2006). Exposition of OVX rats to $E_{2}$ for 4 days up-regulated synthesis rate of substance P (SP), secretoneurin and calcitonin gene-related peptide (CGRP) in a dose-related manner (Gangula et al., 2000; Mowa et al., 2003a). This effect may be reversed by pretreatment of cultured neurons with a ERs blocker, ICI 182,780 (Mowa et al., 2003a). On the other hand, it appears that long-term treatment (90 days) with $\mathrm{E}_{2}$ down-regulates $\beta$-preprotachykinin ( $\beta$-PPT) mRNA encoding SP (Liuzzi et al., 1999), implying that there may be several mechanism through which $\mathrm{E}_{2}$ acts, depending on the physiological conditions and the duration of exposure to it. The functional significance of particular subpopulations of ERs, expressed in L6-S1 DRG sensory neurons in the course of the pregnancy is as yet unclear. However, it should be emphasize that an increase in the content of ER $\alpha$ near term occurred parallel with augmentation of plasma oestrogens as well as SP and CGRP (Mowa et al., 2003a). According to Mowa and Papka (2004), augmentation of SP and CGRP synthesis in response to $\mathrm{E}_{2}$, and further, their antidromic release from sensory terminals supplying the cervical microvasculature lead, in turn, to cervical ripening and consequently, to the initiation of birth process.

\section{Effect of $E_{2}$ on mechanism of analgesia}

It is generally accepted that painful stimuli are predominantly conveyed by processes of small-diameter afferent DRG neurons that, in their majority, synthesize a "nociceptive" peptide - SP, encoding, as mentioned above, by $\beta$-PPT gene 
(Gibbins et al., 1987). Expression of this gene, as well as NGF TrkA receptor gene occurred in the same neurons, and is regulated by NGF (Lindsay and Harmar, 1989; Wright and Snider, 1995). However, it has also been found that $\mathrm{E}_{2}$ may affect $\beta$-PPT gene expression in DRG cells, acting indirectly by influencing TrkA receptor gene expression, although this action depend on the exposition time to $\mathrm{E}_{2}$. Long-term ( 90 days) $\mathrm{E}_{2}$ replacement decreased lumbar DRG TrkA and $\beta$-PPT mRNA levels in adult OVX rats, while short-term (2 days) $\mathrm{E}_{2}$ replacement was able to increase levels of mRNA encoding these substances. In turn, in lumbal DRG neurons, which have had their processes cut in the sciatic nerve in order to deprive of target-derived NGF, $\mathrm{E}_{2}$ increased level of mRNA for TrkA, but simultaneously suppressed $\beta$-PPT gene expression (Liuzzi et al., 1999, 2001), conforming the hypothesis that $\mathrm{E}_{2}$ may effect on this gene only in the presence of NGF.

\section{LOCALIZATION, EXPRESSION AND PUTATIVE FUNCTIONS OF ANDRO- GEN RECEPTORS (ARs) IN THE PNS}

\section{Distribution pattern of ARs in autonomic neurons and other cells}

It is generally accepted that many, if not virtually all of pelvic autonomic neurons in male rats change their morphology and function(s) after androgen deprivation. It should also be stressed, that changes in the level of circulating testosterone (T) and its derivates were able to influence not only the autonomic efferent neurons, but also have a profound impact on the morphology and chemical coding of DRGs primary afferent, as well as spinal cord preganglionic neurons.

Regarding the efferent neurons, it should be stressed that the PG are composed of both the sympathetic and the parasympathetic subset of cells. Thus, tyrosine hydroxylase $(\mathrm{TH})$-positive (i.e. sympathetic) neurons were found to form distinct clusters throughout the PG, being intermingled with groups of cholinergic/nitrergic (i.e. parasympathetic) perikarya. Although the sympathetic component was observed in both the intact as well as castrated animals, sympathetic pelvic neurons were noticeably smaller in castrated animals; furthermore, the total number of preganglionic/afferent varicosities per TH-IR neuron in castrated animals was significantly lower than this observed in the control rats (Keast and Saunders, 1998). These data are in line with hypothesis that noradrenergic pelvic neurons in male rats exhibit androgen-sensitivity in the both pre- and post-pubertal periods, as has been judged from results of castration performed at different time points: these neurons either fail to achieve (pre-pubertal castration) or to maintain normal adult soma size (post-pubertal surgery). Furthermore, affected TH-IR neurons showed also a down-regulation in expression of a coexisting peptide, neuropeptide Y (NPY) (Keast and Saunders, 1998). It has also been demonstrated 
that while virtually all noradrenergic pelvic neurons were dramatically affected by castration, the population of cholinergic neurons was not nearly as affected by androgen deprivation as the noradrenergic ones. However, there was a "target tissue/chemical code-dependent susceptibility" to androgens deprivation: neurons supplying the urinary bladder and bowel (and, in their majority, containing NPY) did not change at all after castration, whereas those supplying the penis and glandular tissues of internal reproductive organs (i.e. containing vasoactive intestinal polypeptid -VIP), were consistently smaller after castration (Keast, 1999). This may be explained by the pattern of ARs expression in particular neuronal subsets: they were present in a majority of VIP neurons, but virtually absent from the cholinergic NPY cells (Keast and Saunders, 1998). Furthermore, androgens have also been implicated to play a crucial role in ARs-dependent NOS expression in the VIP-IR pelvic neurons that project to the penile tissues (Schirar et al., 1997a,b). In addition, $\mathrm{T}$ and its derivates have been implied to influence various aspects of neuroeffector transmission, including, besides NOS synthesis (Schirar et al., 1997a) also adenoreceptor(s) expression and involvement in an undefined dilatory mechanism (Reilly et al., 1997).

Watkins and Keast (1999) have demonstrated, by means of retrograde tracing from the major PG, that both lumbar (i.e. sympathetic, located in L1 and L2 neuromeres) and lumbo-sacral (i.e. parasympathetic, found in L6-S1 spinal cord segments) preganglionic neurons of the spinal cord are involved in the control of pelvic neurons and, that the vast majority of these perikarya were simultaneously ARs-IR, as may be judged from clearly visible nuclear staining. Interestingly, both the proportion of retrogradely labelled neurons, that were simultaneously ARs-IR, as well as the intensity of the receptor-immunolabelling, was highly regulated by circulating androgens. A comparison of immunostainings performed on spinal cord sections taken from the lumbar and sacral levels showed, that a distinctly greater proportion $(60-70 \%)$ of parasympathetic preganglionic neurons exhibits ARs-IR, than the sympathetic ones do $(20-40 \%)$. It should be stressed again, that this is in contrast with the pattern of ARs expression in their target - the PG - where only a minority of cholinergic efferent neurons expressed nuclear ARs labelling. Furthermore, as mentioned above, it has also been suggested that androgen(s) deprivation may cause a substantial decrease in the number of sympathetic preganglionic varicosities apposed to particular pelvic neurons (especially the noradrenergic ganglion cells), what strongly suggest that in adult animals $\mathrm{T}$ (or its derivates) is necessary to maintain these circuits intact (Keast and Gleeson, 1998). Thus, the above mentioned data clearly showed that preganglionic autonomic neurons controlling the pelvic efferent neurons are targets for circulating $\mathrm{T}$, and that this steroid hormone may directly affect their properties (Keast and Gleeson, 1998; Watkins and Keast, 1999).

As shortly pointed above, ARs have also been demonstrated to be expressed by DRG sensory neurons. Thus, in an elegant study, Keast and Gleeson (1998) 
have shown that approximately half of the sacral DRG cells in male rats expressed ARs. Astonishingly, a similar numbers of DRG cells have been shown to express ERs (Yang et al., 1998). Regarding the co-existence of known transmitter(s) and ARs in primary afferent neurons, it has been shown that the vast majority of pelvic viscera-supplying lumbar and sacral afferent neurons contained CGRP and that more that $80 \%$ of the CGRP-IR sensory perikarya expressed simultaneously ARs (Kreast and Gleeson, 1998). It has also been suggested that the higher number of such neurons in L6 and S1 ganglia of male adult rats there may be attributable to the circulating androgens level (Mills and Sengelaub, 1993). This may be indirectly supported by observation that ARs-IR was significantly diminished and neurons with clearly visible nuclear staining were rare in castrated animals.

Both ARs mRNA and protein were also found in sciatic nerves of adult rats. ARs-IR was restricted to the nuclei of cells forming the endo- and perineurium of the nerve, both in male and female animals. However, the nerves of males contained nearly threefold more nuclei exhibiting ARs-IR than that found in females (Magnaghi et al., 1999). Moreover, ARs mRNA expression in sciatic nerves of adult males was also higher as compared to that determined in female rats (Jordan et al., 2002). Using RT-PCR it was detected that endoneurial and perineurial fibroblasts and endothelial cells of sciatic nerves are the most prominent ARs-expressing cells and are likely to be the primary source of ARs mRNA. However, one of the major cell populations of this nerve - Schwann cells - does not appear to express ARs in culture (Magnaghi et al., 1999). On the other hand, Jordan et al. (2002) showed very light AR-staining in nuclei of Schwann cells. Thus, the question of the expression pattern of ARs in these cells remains to be solved.

\section{Functional implications for ARs in autonomic neurons}

It is widely accepted that the PNS plays an essential role in penile erection, secretion from the prostate gland and seminal vesicles, propulsion of seminal contents via the epidydymis and vas deferens (de Groat and Booth, 1993; Andersson and Wagner, 1995). All of the male reproductive organs possess a dense autonomic innervation, supplying vascular and non-vascular smooth muscle and glandular epithelia. As many, if not all of autonomic neurons supplying these organs were shown to express ARs (and, even, ERs), the question arises how the circulating androgens may fulfill their regulatory role in these circuits. As of now, there were several suppositions concerning their mode of action: first, $T$ itself may act on neuronal ARs. Secondly, it may be first metabolized to dihydrotestosterone (DHT) by $5 \alpha$-reductase and this metabolite may then activate ARs; this suggestion is supported by the findings that a considerable level of $5 \alpha$-reductase was found at all levels of the rat spinal cord (MacLusky et al., 1987). The third possibility assumed that $\mathrm{T}$ may be aromatized to $\mathrm{E}_{2}$, that may then either affect the ERs found in autonomic neurons as 
a "main" messenger or, may play a "supplementary" role to the T-driving signaling cascade. The last possibility may be explained by an indirect mechanism, where $\mathrm{T} /$ its metabolites may regulate dendric aborization of spinal neurons as well as affect their soma size via neuronal ARs, in a similar way as it has been proposed for motoneurons (Rand and Breedlove, 1995). In vitro studies showed that the decrease in PG soma size caused by gonadectomy could be prevented by administration of $\mathrm{T}$ or DHT but not $\mathrm{E}_{2}$, showing that this maintenance action of $\mathrm{T}$ is mediated entirely by androgenic mechanism. In turn, in the cultured PG neurons showed that these androgens and $\mathrm{E}_{2}$ stimulated the growth of longer and more complex neuritis in both noradrenergic and cholinergic NOS-expressing neurons. These results revealed that the effects of androgens on axonal growth are likely to be at least partly mediated by oestrogenic mechanisms, which may be important for understanding disease-, aging- and injury-induced plasticity in the PNS (Purves-Tyson et al., 2007).

As mentioned above, circulating androgens have potent effect on the structure and function of many pelvic neurons in adult rat in vivo. For example, $\mathrm{T}$ was found to be a much more potent stimulant of noradrenergic cells growth in the culture than NGF itself, however, it was also able to impede the enlargement of long neurites (which was induced and maintained by NGF), being, however, able to stimulate simultaneously the development and growth of short neuronal processes (Meusburger and Keast, 2001). However, it should be stressed that the effect(s) exerted by circulating androgens were restricted to neurons supplying "androgenresponsive" target organs. This allow to explain the observation that there was no obvious decrease in size of the rectum- or urinary bladder-projecting perikarya, what strongly suggests that affected neurons are not smaller in androgen-deprived animals simply due to a lowered titters of available hormone/its metabolites (Keast, 1999). Furthermore, it has been demonstrated that androgens also exert strong effect(s) on the maturation and maintenance of number of neuronal pathways involved in reproductive behaviours in male. Although most studies in this area have been focused on central pathways, there is growing body of evidence that ARs are deeply involved in structural and chemical changes in the neural pathways controlling reproductive organs at puberty as well as after castration (de Groat and Booth, 1993; Kanjhan et al., 2003). Various studies have strongly implicated androgens in maintaining the optimal function of the penile erection reflex (Anderson and Wagner, 1995; Burnett, 2003).

\section{LOCALIZATION, EXPRESSION AND PUTATIVE FUNCTIONS OF PRO- GESTAGEN RECEPTORS (PRs) IN THE PNS}

The presence of PRs protein and mRNA transcripts has been described in Schwann cells of sciatic nerves of newborn (4-5 days) and adult female and male 
rats (Jung-Testas at al., 1996; Martini et al., 2003). However, in contrast to oestrogen-induced PRs expression in rat CNS glial cells, an exposure of sciatic nerve Schwann cells harvested from newborn rats to $\mathrm{E}_{2}$ did not enhance the expression pattern of PRs in these cells. Similarly, also administration of $E_{2}$ in OVX adult female rats did not induce any changes in the expression of PRs in the cytosol of sciatic nerve Schwann cells (Jung-Testas et al., 1996). In contrary, $\mathrm{E}_{2}$ increased in dose-dependent manner the content of PRs in co-cultures of rat foetal DRG neurons/Schwann cells. However, exposure of these co-cultures to oestrogen antagonist (ICI 164,384) completely inhibited $\mathrm{E}_{2}$-induced PRs expression. Moreover, excision of the neuronal mass from DRG neurons/Schwann cells co-cultures caused a rapid decrease and disappearance of $\mathrm{E}_{2}$-inducible PRs in Schwann cells, whereas the concentration of non-inducible PR binding sites remained unchanged (Thi et al., 1998). It has also been shown that expression of PRs in DRG neurons and their translocation into the nuclei significantly increased in response to $\mathrm{P}_{4}$ or during myelin synthesis (Chan et al., 2000).

\section{Effect of $\mathrm{P}_{4}$ and its derivatives on the morphology of myelin sheaths and axons}

It has been reported that $\mathrm{P}_{4}$ and its derivates (5 $\alpha$-dihydroprogesterone - $5 \alpha$ DHP and $3 \alpha, 5 \alpha$-tetrahydroprogesterone - $3 \alpha, 5 \alpha$-THP) were able to change the morphological parameters of the myelin compartment of the sciatic nerves of 22-24-month-old male rats. These neuroactive steroids have clear effect on the number and shape of myelinated fibres as well as on the frequency of myelin abnormalities. For example, $\mathrm{P}_{4}$ and its derivates increased the number of small myelinated fibres but not larger fibres. This increase was accompanied by a decrease in the number of unmyelinated axons. Furthermore, progestagens reduced the frequency of occurrence of axons with myelin abnormalities, mainly axons with myelin infoldings and with irregular shapes, in other words, with morphological changes associated with aging of sciatic nerve (Melcangi et al., 2003a). It has also been indicated that not only myelin, but also the axonal compartment may be considered as a target for $\mathrm{P}_{4}$ influence (Melcangi et al., 2005). Treatment of rat sciatic nerves with an abortion-inducing drug mifepristone (a $\mathrm{P}_{4}$ receptor antagonist) from the first day of life till the day 30 lead to a reduction in fibre diameter and to an increase in the number of axons with smaller diameter. This decrease in the axonal diameter may be related to a reduction in axon diameter rather, than to a thinning of the myelin sheaths (Melcangi et al., 2003b, 2005). Rodriguez-Waitkus et al. (2003) indicated that $\mathrm{P}_{4}$ reduces the time required for the initiation of myelin formation and enhances the rate of myelin synthesis in Schwann cell/neuronal co-cultures, in a dose dependent manner. It was also showed that the mRNAs for cholesterol side-chain cleavage cytochrome $\mathrm{P}_{450}$ and $3 \beta$-hydroxysteroid dehydrogenase (enzymes involved in $\mathrm{P}_{4}$ biosynthesis) were induced at the onset of myelin 
synthesis. Moreover, the PRs protein translocated into the nucleus of the neurons during myelin synthesis suggesting that $\mathrm{P}_{4}$ could also be affecting neuronal gene expression.

Effect of $P_{4}$ and its derivatives on the expression of myelin proteins and Schwann cell proliferation

Treatment of adult male rats with $\mathrm{P}_{4}, 5 \alpha$-DHP or $3 \alpha, 5 \alpha$-THP lead to an increase in glycoprotein Po (Po) mRNA level in sciatic nerve (Melcangi et al., 2003b; Hara et al., 2007). In turn, in the same experimental model, the mRNA level of peripheral myelin protein 22 (PMP22) was elevated only after administration of $3 \alpha, 5 \alpha$-THP (Melcangi et al., 2003b). $\mathrm{P}_{4}$ and its derivates were also able to stimulate the expression of these two myelin proteins in aged male rats (Melcangi et al., 1998) as well as to augment the expression of Po in response to peripheral nerve injury (Melcangi et al., 2000; Hara et al., 2007). $\mathrm{P}_{4}$ is not only able to influence the expression of myelin proteins by Schwann cells but also, in similarity to $\mathrm{E}_{2}$, to affect the proliferation of these cells. It was found that $\mathrm{P}_{4}$ increased Schwann cell proliferation obtained from sciatic nerve of adult female and newborn rats, and this effect was blocked by its respective receptor antagonist (Svenningsen and Kanje, 1999).

\section{CONCLUSIONS}

In conclusion, data presented in this short review concerned the presence and putative relevance of ERs, ARs and PRs in sensory and autonomic neurons supplying the genito-urinary system in rat, the only species studied in this respect so far. Moreover, it should be stressed that these receptors were also present in Schwann cell/DRG neurons contributing to sciatic nerves, thus may be implicated in (neuro)steroid-driven maintenance of somatosensory pathways. It has further been documented that within the PNS, oestrogens are not only involved in mechanisms controlling the developing, survival, plasticity (i.e. changes in the chemical phenotypes of sensory neurons projecting to the female reproductive organs), repair and neuritogenesis of sensory and autonomic neurons, but also in the regulation of Schwann cell proliferation, and mechanism of analgesia. On the other hand, androgens appear to exert strong influence on the morphology, neurochemical coding and functions of pelvic autonomic neurons involved in many reproductive behaviours in males (for example, penile erection or semen ejaculation), while progestagens were involved in the establishing of the final morphology of myelin sheaths and axons, expression of myelin proteins as well as proliferation of Schwann cells. As may be judged from the available literature, it appears really 
important to estimate the distribution and expression pattern of steroid hormones receptors in the PNS of other mammalian species, as this will provide us with better understanding of putative effect(s) of (neuro)steroid hormones on cell functions in this system. This, in turn, may permit the understanding of physiological and pathological processes not only in animals, but also in humans, what may have a sounding practical importance.

\section{REFERENCES}

Andersson K.E., Wagner G., 1995. Physiology of penile erection. Physiol. Rev. 75, 191-236

Bajusz E., 1959. Effect of hormones upon regression of muscle atrophy of nervous origin. Endocrinology 64, 262-269

Bennett H.L., Gustafsson J.A., Keast J.R., 2003. Estrogen receptor expression in lumbosacral dorsal root ganglion cells innervating the female rat urinary bladder. Auton. Neurosci. 105, 90-100

Brauer M.M., Chávez-Genaro R., Llodrá J., Richeri A., Scorza M.C., 2000. Effects of chronic oestrogen treatment are not selective for uterine sympathetic nerves: a transplantation study. J. Anat. 196, 347-355

Brauer M.M., Chávez-Genaro R., Richeri A., Viettro L., Frias A.I., Burnstock G., Cowen T., 2002. The oestrogenized rat myometrium inhibits organotypic sympathetic reinnervation. Auton. Neurosci. 101, 13-22

Burnett A.L., 2003. Neurophysiology of erectile function: Androgenic effects. J. Andrology 24, 2-5

Chan J.R., Rodriguez-Waitkus P.M., Ng B.K., Liang P., Glaser M., 2000. Progesterone synthesized by Schwann cells during myelin formation regulates neuronal gene expression. Mol. Biol. Cell $11,2283-2295$

Chávez-Genaro R., Crutcher K., Viettro L., Richeri A., Coirolo N., Burnstock G., Cowen T., Brauer M.M., 2002. Differential effects of oestrogen on developing and mature uterine sympathetic nerves. Cell Tissue Res. 308, 61-73

de Groat W.C., Booth A.M., 1993. Neuronal control of the penile erection. In: C.A. Maggi (Editor). Nervous Control of the Urogenital System. Harwood Academic Publishers, Chur (Switzerland), pp. 467-524

Gangula P.R.R., Lanlua P., Wimalawansa S.J., Supowit S., DiPette D., Yallampalli C., 2000. Regulation of calcitonin gene-related peptide expression in dorsal root ganglia of rats by female sex steroid hormones. Biol. Reprod. 62, 1033-1039

Gibbins I.L., Furness J.B., Costa M., 1987. Pathway-specific patterns of the co-existence of substance $\mathrm{P}$, calcitonin gene-related peptide, cholecystokinin and dynorphin in neurons of the dorsal root ganglia of the guinea-pig. Cell Tissue Res. 248, 417-437

Hara Y., Ochiai N., Abe I., Ichimura H., Saijilafu, Nishiura Y., 2007. Effect of progesterone on recovery from nerve injury during leg lengthening in rats. J. Bone Joint Surg.- Brit. 89, 830-835

Jordan C.L., Price Jr. R.H., Handa R.J., 2002. Androgen receptor messenger RNA and protein in adult rat sciatic nerve: implications for site of androgen action. J. Neurosci. Res. 69, 509-518

Jung-Testas I., Schumacher M., Bugnard H., Baulieu E.E., 1993. Stimulation of rat Schwann cell proliferation by estradiol: synergism between the estrogen and cAMP. Develop. Brain Res. 72, 282-290

Jung-Testas I., Schumacher M., Robel P., Baulieu E.E., 1996. Demonstration of progesterone receptors in rat Schwann cells. J. Steroid Biochem. Mol. Biol. 58, 77-82 
Kanjhan R., Osborne P.B., Ouyang M., Keast J.R., 2003. Postnatal maturational changes in rat pelvic autonomic ganglion cells: A mixture of steroid-dependent and-independent effects. J. Neurophysiol. 89, 315-323

Keast J.R., 1999. The autonomic nerve supply of male sex organs - an important target of circulating androgens. Behav. Brain Res. 105, 81-92

Keast J.R., Gleeson R.J., 1998. Androgen receptor immunoreactivity is present in primary sensory neurons of male rats. Neuroreport 9, 4137-4140

Keast J.R., Saunders R.J., 1998. Testosterone has potent, selective effects on the morphology of the pelvic autonomic neurons which control the bladder, lower bower and internal reproductive organs of the male rat. Neuroscience 85, 543-556

Krizsan-Agbas D., Smith P.G., 2002. Estrogen modulates myometrium-induced sympathetic neurite formation through actions on target and ganglion. Neuroscience 114, 339-347

Lindsay R.M., Harmar A.J., 1989. Nerve growth factor regulates expression of neuropeptide genes in adult sensory neurons. Nature 337, 362-364

Liuzzi F.J., Bufton S.M., Scoville S.A., 2001. Short-term estrogen replacement increases $\beta$-preprotachykinin mRNA levels in uninjured dorsal root ganglion neurons, but not in axotomized neurons. Exp. Neurol. 170, 101-108

Liuzzi F.J., Scoville S.A., Bufton S.M., 1999. Long-term estrogen replacement coordinately decreases trkA and $\beta$-PPT mRNA levels in dorsal root ganglion neurons. Exp. Neurol. 155, 260-267

MacLusky N.J., Clark C.R., Shanabrough M., Naftolin F., 1987. Metabolism and binding of androgens in the spinal cord of the rat. Brain Res. 422, 83-91

Magnaghi V., Cavarretta I., Zucchi I., Susani L., Rupprecht R., Hermann B., Martini L., Melcangi R.C., 1999. Po gene expression is modulated by androgens in the sciatic nerve of adult male rats. Mol. Brain Res. 70, 36-44

Martini L., Magnaghi V., Melcangi R.C., 2003. Actions of progesterone and its $5 \alpha$-reduced metabolites on the major proteins of the myelin of the peripheral nervous system. Steroids 68, 825-829

Melcangi R.C., Azcoitia I., Ballabio M., Cavarretta I., Gonzalez L.C., Leonelli E., Magnaghi V., Veiga S., Garcia-Segura L.M., 2003a. Neuroactive steroids influence peripheral myelination: a promising opportunity for preventing or treating age-dependent dysfunctions of peripheral nerves. Prog. Neurobiol. 71, 57-66

Melcangi R.C., Ballabio M., Cavarretta I., Gonzales L.C., Leonelli E., Veiga S., Martini L., Magnaghi V., 2003b. Effects of neuroactive steroids on myelin of peripheral nervous system. J. Steroid Biochem. Mol. Biol. 85, 323-327

Melcangi R.C., Cavarretta I.T.R., Ballabio M., Leonelli A.S., Azcoitia I., Garcia-Segura L.M., Magnaghi V., 2005. Peripheral nerves: a target for the action of neuroactive steroids. Brain Res. Rev. 48, 328-338

Melcangi R.C., Magnaghi I., Cavarretta L., Martini L., Piva F., 1998. Age-induced decrease of glycoprotein Po and myelin basic protein gene expression in the rat sciatic nerve. Repair by steroid derivatives. Neuroscience 85, 569-578

Melcangi R.C., Magnaghi V., Galbiati M., Ghelarducci B., Sebastiani L., Martini L., 2000. The action of steroids hormones on peripheral myelin proteins: A possible new tool for the rebuilding of myelin? J. Neurocytol. 29, 327-339

Meusburger S., Keast J.R., 2001. Testosterone and nerve growth factor have distinct but interacting effects on structure and neurotransmitter expression of adult pelvic ganglion cells in vitro. Neuroscience 108, 331-340

Mills A.C., Sengelaub D.R., 1993. Sexually dimorphic neuron number in lumbosacral dorsal root ganglia of the rat: development and steroid regulation. Neurobiology 24, 1543-1553 
Mowa C.N., Collins J., Usip S., Storey-Workley M., Amann R., Papka R., 2003a. Substance P in the uterine cervix, dorsal root ganglia and spinal cord during pregnancy and the effect of estrogen on SP synthesis. Peptides 5, 761-771

Mowa C.N., Papka R.E., 2004. The role of sensory neurons in cervical ripening: effect of estrogen and neuropeptides. J. Histochem. Cytochem. 52, 1249-1258

Mowa C.N., Usip S., Storey-Workley M., Hargreaves K., Papka R., 2003b. Effect of estrogen and pregnancy on calcitonon gene-related peptide expression in the uterine cervix, dorsal root ganglia and spinal cord. Peptides 8, 1163-1174

Nicol G.D., Vasko M.R., 2007. Unraveling the story of NGF-mediated sensitization of nociceptive sensory neurons: on or off the Trks? Mol. Interv. 7, 26-41

Oppenheim R.W., 1991. Cell death during development of the central nervous system. Ann. Rev. Neurosci. 14, 453-501

Papka R.E., Srinivasan B., Miller K.E., Hayashi S., 1997. Localization of estrogen receptor protein and estrogen receptor messenger RNA in peripheral autonomic and sensory neurons. Neuroscience 79, 1153-1163

Papka R.E., Storey-Workley M., 2002. Estrogen receptor-alpha and -beta coexist in a subpopulation of sensory neurons of female rat dorsal root ganglia. Neurosci. Lett. 319, 71-74

Papka R.E., Storey-Workley M., Shughrue P.J., Merchenthaler L., Collins J.J., Usip S., Saunders P.T., Shupnik M., 2001. Estrogen receptor-alpha and beta-immunoreactivity and mRNA in neurons of sensory and autonomic ganglia and spinal cord. Cell Tissue Res. 304, 193-214

Patrone C., Andersson S., Korhonen L., Lindholm D., 1999. Estrogen receptor-dependent regulation of sensory neuron survival in developing dorsal root ganglion. Neurobiology 96, 10905-10910

Purves-Tyson T.D., Arshi M.S., Handelsman D.J., Cheng Y., Keast J.R., 2007. Androgen and estrogen receptor-mediated mechanisms of testosterone action in male rat pelvic autonomic ganglia. Neuroscience 148, 92-104

Rand M.N., Breedlove S.M., 1995. Androgen alerts the dendritic arbor of SNB motoneurons by acting upon their target muscles. J. Neurosci. 15, 4408-4416

Reilly C.M., Lewis R.W., Stopper V.S., Mills T.M., 1997. Androgenic maintenance of the rat erectile response via a non-nitric-oxide-dependent pathway. J. Andrology 18, 588-594

Rodriguez-Waitkus P.M., Lafollette A.J., Ng B.K., Zhu T.S., Conrad H.E., Glaser M., 2003. Steroid hormone signaling between Schwann cells and neurons regulates the rate of myelin synthesis. Ann. N.Y. Acad. Sci. 1007, 340-348

Schirar A., Bonnefond C., Meusnier C., Devinoy E., 1997b. Androgens modulate nitric oxide synthase messenger ribonucleic acid expression in neurons of the major pelvic ganglion in the rat. Endocrinology 138, 3093-3102

Schirar A., Chang C., Rousseau J.P., 1997a. Localization of androgen receptor in nitric oxide synthase- and vasoactive intestinal peptide-containing neurons of the major pelvic ganglion innervating the rat penis. J. Neuroendocrinol. 9, 141-150

Schmitt P.M., Gohil K., Kaufman M.P., 2006. Spinal estrogen attenuates the exercise pressor reflex but has little effect on the expression of genes regulating neurotransmitters in the dorsal root ganglia. J. Appl. Physiol. 100, 958-964

Scoville S.A., Bufton S.M., Liuzzi F.J., 1997. Estrogen regulates neurofilament gene expression in adult female rat dorsal root ganglion neurons. Exp. Neurol. 146, 596-599

Shinohara Y., Matsumoto A., Hayashi S., Mori T., 2000. Prenatal exposure to diethylstilbestrol decreases the number of estrogen receptor alpha-containing neurons innervating the ovary in rat celiac ganglion. Neuroscience 101, 779-783

Sohrabiji F., Miranda R.C., Toran-Allerand C.D., 1994. Estrogen differentialy regulates estrogen and nerve growth receptor mRNAs in adult sensory neurons. J. Neurosci. 14, 459-471 
Svenningsen A.F., Kanje M., 1999. Estrogen and progesterone stimulate Schwann cell proliferation in a sex- and age-dependent manner. J. Neurosci. Res. 57, 124-130

Taleghany N., Sarajari S., DonCarlos L.L., Gollapudi L., Oblinger M.M., 1999. Differential expression of estrogen receptor alpha and beta in rat dorsal root ganglion neurons. J. Neurosci. Res. 57, 603-615

Thi A.D., Jung-Testas I., Baulieu E.E., 1998. Neurnonal signals are required for estrogen-mediated induction of progesterone receptor in cultured rat Schwann cells. J. Steroid Biochem. Mol. Biol. 67, 201-211

Vogelbaum M.A., Tong J.X., Rich M.K., 1998. Developmental regulation of apoptosis in dorsal root ganglion neurons. J. Neurosci. 18, 8928-8935

Watkins T.W., Keast J.R., 1999. Androgen-sensitive preganglionic neurons innervate the male rat pelvic ganglion. Neuroscience 93, 1147-1157

Wright D.E., Snider W.D., 1995. Neurotrophin receptor mRNA expression defines distinc populations of neurons in rat dorsal root ganglia. J. Comp. Neurol. 351, 329-338

Yang Y., Ozawa H., Lu H., Yuri K., Hayashi S., Nihonyanagi K., Kawata M., 1998. Immunocytochemical analysis of sex differences in calcitonin gene-related peptide in the rat dorsal root ganglion, with special reference to estrogen and its receptor. Brain Res. 791, 35-42

Zoubina E.V., Smith P.G., 2002. Distributions of estrogen receptors alpha and beta in sympathetic neurons of female rats: enriched expression by uterine innervation. J. Neurobiol. 52, 14-23

Zoubina E.V., Smith P.G., 2003. Expression of estrogen receptors alpha and beta by sympathetic ganglion neurons projecting to the proximal urethra of female rats. J. Urol. 1, 382-385 